\title{
Microstructure and Properties of Fe-Based Coating on Column Surface Formed by High Frequency Induction Cladding
}

\author{
Huilong Yang, Yufu Sun, Jingjie Shen, Sumeng Hu, Qing Zhao, Xiangcai Jia, Jingchao Zhang
}

School of Materials Science and Engineering, Zhengzhou University, Zhengzhou, China.

Email: yufusun@zzu.edu.cn

Received September $18^{\text {th }}, 2011$; revised October $29^{\text {th }}, 2011$; accepted November $8^{\text {th }}, 2011$

\begin{abstract}
The Fe-based coating was produced on the surface of the column substrate with a $\mathrm{Al}_{2} \mathrm{O}_{3}$ cylindrical sleeve by high frequency induction cladding, microstructure of the coating was investigated with scanning electron microscope (SEM), the crystal structure was characterized by X-ray diffractometer (XRD), the microhardness and wear resisitance of the coating were evaluated. The results show that a metallurgical bond between coating and substrate was obtained during the rapid solidification, the phases of the coating were composed of austenite and the eutectic of $\gamma-\mathrm{Fe}+(\mathrm{Cr}, \mathrm{Fe})_{7}(\mathrm{C}, \mathrm{B})_{3}$. Compared with the substrate, the microhardness and wear resistance of the coating improved apparently, solid-solution strengthening and second-phase particle hardening led to these results.
\end{abstract}

Keywords: High Frequency Induction Cladding; Fe-Based Coating; Microstructure; Wear Resisitance

\section{Introduction}

Wear of machinery components is one of the most common problems in engineering application [1]. Surface coating is usually used to increase the wear resistance of the wear components. There are many surface coating techniques, such as thermal spraying, bead welding, plasma spraying, laser cladding, chemical and physical vapor deposition processes [2-4]. Due to the advantages in high heating efficiency, rapid heating speed, good controlability, easy mechanization and automation, high frequency induction heating as a developing technique has been applied more and more widely in surface coating. Most of researches on high frequency induction cladding focused on the planar workpiece, but few studies on the cylinder, cone and other rotational parts were reported.

In this paper, $\mathrm{Al}_{2} \mathrm{O}_{3}$ cylindrical sleeves were coordinated to produce the Fe-based coating on column surface by high frequency induction cladding, the microstructure and crystal structure of the coating were characterized, microhardness and wear resisitance were also investigated.

\section{Experimental Procedure}

A low carbon steel was used as the substrate material. Column with a dimension of $\varnothing 36 \mathrm{~mm} \times 40 \mathrm{~mm}$ was ma- chined on a C6140 lathe. Fe-based alloy powder was used as the coating material, the chemical composition of Fe-based alloy powder is shown in Table 1. The size of the particles ranged from 58 to $150 \mu \mathrm{m}$.

The high frequency induction heating equipment (SGD-60B) was adopted as the experimental apparatus, the surface cladding processing parameters were described as follows: maximum power output: $60 \mathrm{~kW}$; output oscillation frequency: $50-150 \mathrm{kHz}$; heating electric current: 10 - $70 \mathrm{~A}$; pressure of cooling water: $\geq 0.2 \mathrm{Mpa}$; turns of induction copper coil: 3 ; diameter of induction coil: $50 \mathrm{~mm}$; spacing of induction coils: $5 \mathrm{~mm}$. Figure 1 shows a schematic profile of high frequency induction cladding sample with a $\mathrm{Al}_{2} \mathrm{O}_{3}$ cylindrical sleeve on column surface. The $\mathrm{Al}_{2} \mathrm{O}_{3}$ cylindrical sleeve equiped with silicate bonded sand bottom block should be preheated for $1.5 \mathrm{~h}$ at $300^{\circ} \mathrm{C}$ and another $1.5 \mathrm{~h}$ at $600^{\circ} \mathrm{C}$. During the cladding, the assembled sample was put into the induction coil in vertical and kept heating for $40 \mathrm{~s}$, then taken out of the coil.

The analysis specimens were taken from the transverse intersection along the vertical direction of column sur-

Table 1. Chemical composition of Fe-based alloy.

\begin{tabular}{ccccccc}
\hline Elements & $\mathrm{C}$ & $\mathrm{Cr}$ & $\mathrm{Ni}$ & $\mathrm{B}$ & $\mathrm{Si}$ & $\mathrm{Fe}$ \\
\hline Content (wt\%) & $3.5-4.5$ & $28-32$ & $8-12$ & $1-2$ & $1.5-3$ & Balance \\
\hline
\end{tabular}




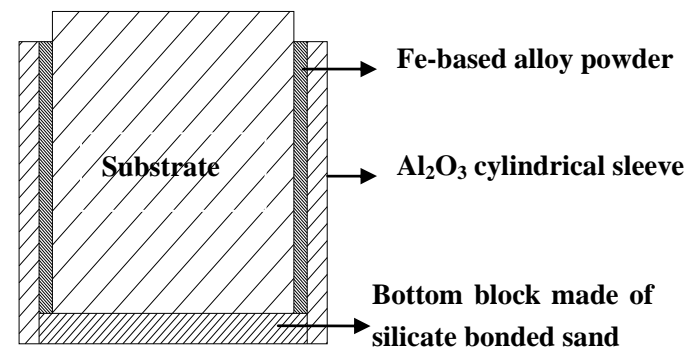

Figure 1. Schematic profile of the assembled sample.

face. The metallographic specimens were grinded with silicon carbide emery paper of 100 - 800 grit size, polished with diamond paste by an automatic polishing machine and etched with $4 \%$ nital. The microstructure of the coating was observed by a scanning electron microscope (SEM, Quanta-2000), the phases were identified by X-ray diffraction (XRD, Philips x'pert Pro). Microhardness was measured using a HX-1000 TM/LCD Vickers hardness tester with $300 \mathrm{~N}$ load for $15 \mathrm{~s}$. The wear resistance of the coating was evaluated on ML-100 rotary abrasive machine, the wear tests were operated under 15 $\mathrm{N}$ load and rotational speed of $60 \mathrm{r} / \mathrm{min}$, the mass of the specimens was measured by a precise electronic balance in accuracy of $0.1 \mathrm{mg}$.

\section{Results and Discussion}

\subsection{Microstructure}

The SEM micrographs of the coating are shown in Figure 2. It can be seen that the thickness of the coating is about $2.5 \mathrm{~mm}$, and the coating is fully dense and uniform (Figure 2(a)). High frequency induction cladding is a process of rapid heating and rapid solidification [5]. The protection of the $\mathrm{Al}_{2} \mathrm{O}_{3}$ cylindrical sleeve and the rapid solidification result in the minimal oxidation of the coating. Figure 2(b) shows that the structure of the coating grows towards an explicit direction, this is because intensive eddy emerges in the interface where elctromagnetic properties differ a lot, leading to the highest temperature at the interface. With the effect of heat transfer direction, dendrite crystallization grows along the direction of outside surface. There is a white band between the coating and the substrate (Figure 2(c)), the band results from the diffusion between the coating and substrate, which illustrates that an excellent metallurgical bond is attained. During solidification, the planar crystallization can be observed at the interface, with the increasing of the distance from the bottom of the coating, the microstructure changed into dendrite with eutectic structure (Figure 2(c)).

Figure 3(a) shows the XRD pattern of the coating, it can be seen that the main phases are austenite $\gamma$-Fe and
$(\mathrm{Cr}, \mathrm{Fe})_{7}(\mathrm{C}, \mathrm{B})_{3}[6]$. And in the big block area there is the precipitation of austenite $\gamma$-Fe, which is a non-equilibrium solid solution with supersaturated alloyed elements like $\mathrm{Cr}, \mathrm{Si}, \mathrm{Ni}, \mathrm{B}$ and $\mathrm{C}$, and the other area is the eutectic of $\gamma$-Fe and carboborides (Figure 3(b)).

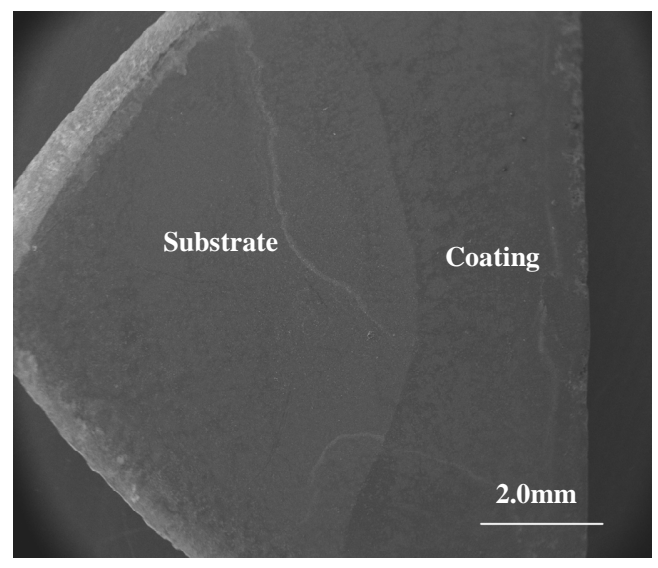

(a)

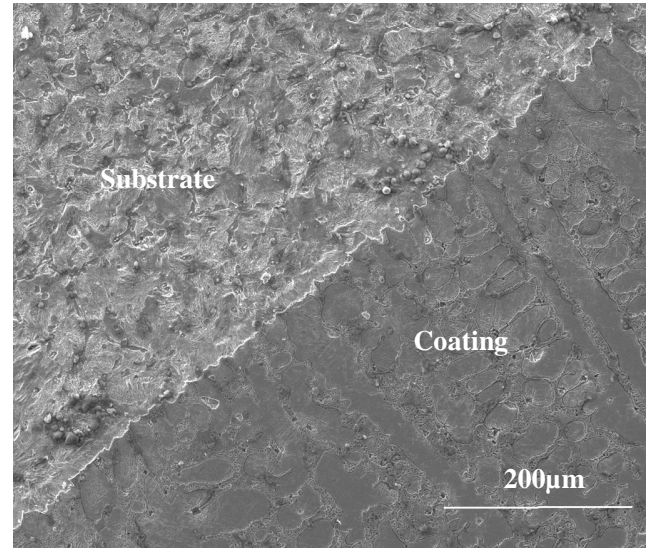

(b)

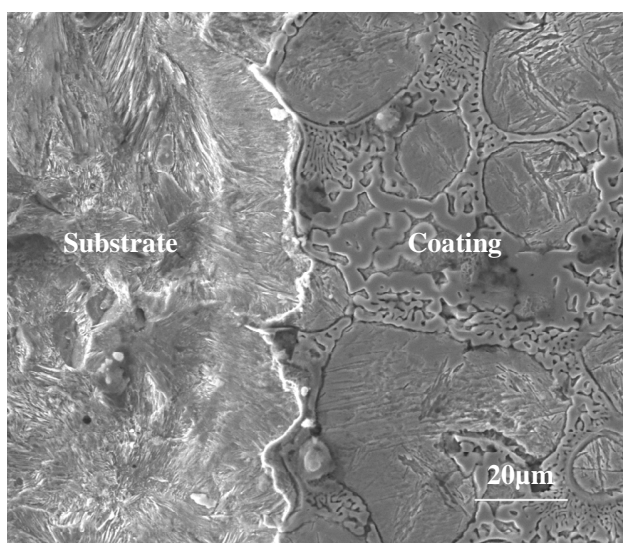

(c)

Figure 2. (a) SEM image showing the overview transverse specimen; (b) SEM image with the interface (200×); (c) SEM image with the interface $(1000 \times)$. 


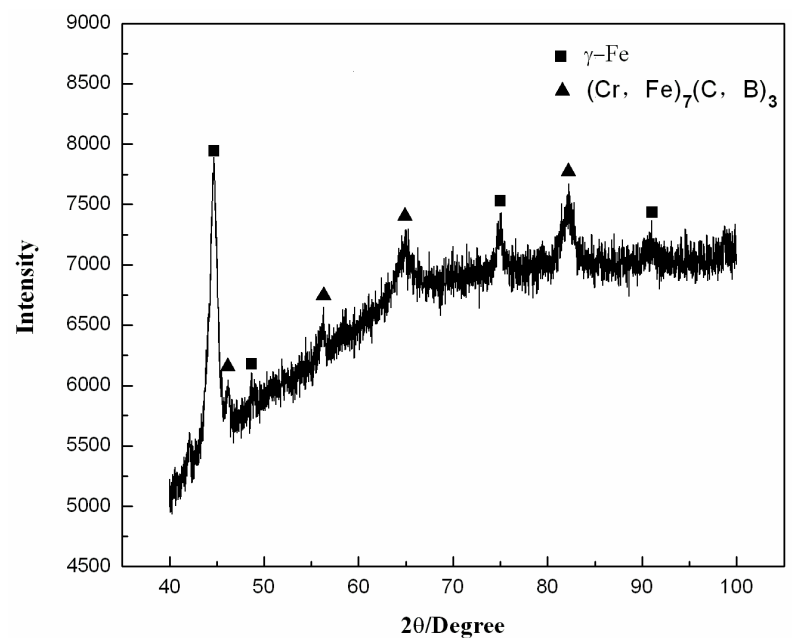

(a)

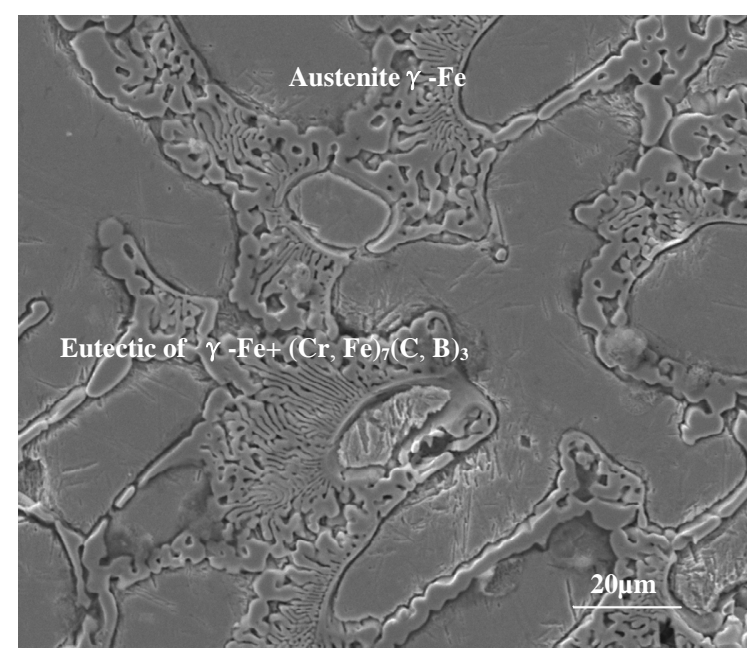

(b)

Figure 3. (a) XRD patterns of the Fe-based coating; (b) Locations of the main phase constituents.

\subsection{Microhardness and Wear Resistance}

Figure 4 displays a microhardness profile of Fe-based coating. It can be seen that the microhardness of the coating keeps nearly stable, the microhardness of the substrate is about $\mathrm{HV}_{0.3} 275$ - 320, while the average microhardness of the coating reaches up to $\mathrm{HV}_{0.3} 980.4$, which is about three times as much as the substrate. We can clearly see that there are kinds of alloy elements in the alloy powder, and the high microhardness of the coating stems from hard phases formed in the process of melting and solidification, such as carbides, borides and carboborides. Moreover, it is mentionable that microhardness near the interface in the coating is higher than other spots, it may because that this area keeps melting for a longer time which leads solid-solution strengthening of the austenite and the eutectic carbides. It was reported

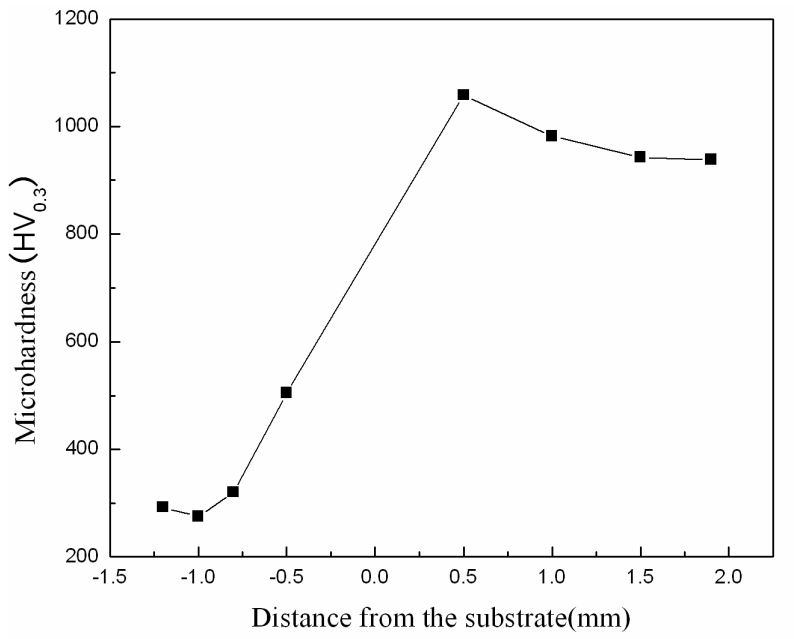

Figure 4. Microhardness profile of Fe-based composite coating.

that the hardness of both matrix and carbide phases determines the hardness of the coating [7]. The high microhardness of the coating is ensured by solid-solution strengthening and second-phase particle hardening.

The wear mass loss of the coating was $0.0872 \mathrm{~g}$ and that of the substrate was $0.2048 \mathrm{~g}$ in wear test. The wear resistance of Fe-based coating increases by $135 \%$ compared with the substrate, which shows the Fe-based coating has excellent wear resistance. The wear resistance improves generally with increasing hardness [8]. So the improvement in wear resistance may be closely related to the high hardness of coating. It can be concluded that the significant improvement of wear resistance is ascribed to solid-solution strengthening and second-phase particle hardening.

Compared with other surface coating technologies, using high frequency induction cladding with a $\mathrm{Al}_{2} \mathrm{O}_{3}$ cylindrical sleeve to produce a coating on the surface of column substrate can get the metallurgical bond between substrate and coating. The heat-affected depth of the substrate is smaller and the processing efficiency is higher. Moreover, the coating materials are variable according to different conditions of the workpiece, such as wear-resistant coatings and corrosion-resistance coatings.

\section{Conclusions}

A Fe-based coating has been successfully produced on column surface by means of high frequency induction cladding with a $\mathrm{Al}_{2} \mathrm{O}_{3}$ cylindrical sleeve, the coating is fully dense and uniform, and has an excellent metallurgical bond with the substrate. The coating crystallization grows along the direction of outside surface from the interface, the results of XRD analysis show that the main phases of the coating are austenite $\gamma$-Fe and eutectic car- 
bide $(\mathrm{Cr}, \mathrm{Fe})_{7}(\mathrm{C}, \mathrm{B})_{3}$. The average microhardness of the coating reaches up to $\mathrm{HV}_{0.3} 980.4$, which is about three times as much as the substrate. The wear resistance of Fe-based coating increases by $135 \%$ compared with the substrate, which should be due to solid-solution strengthening and second-phase particle hardening.

The technology of high frequency induction cladding can be used to produce an excellent coating on the surface of column, cone and other rotational parts, and will get more extensive application in engineering.

\section{REFERENCES}

[1] X. H. Wang, Z. D. Zou, S. Y. Qu and S. L. Song, "Microstructure and Wear Properties of Fe-Based Hardfacing Coating Reinforced by TiC Particles," Journal of Materials Processing Technology, Vol. 168, No. 1, 2005, pp. 89-94. doi:10.1016/j.jmatprotec.2004.11.001

[2] M. Yan, "An Experimental Study of the Remelting of an Fe-C-Cr-Si-B Overlay with a Microbeam Plasma Arc," Surface and Coatings Technology, Vol. 99, No.1-2, 1998, pp. 132. doi:10.1016/S0257-8972(97)00419-2

[3] H. Chen and H.-Q. Li, "Microstructure and Wear Resistance of Fe-Based Coatings Formed by Plasma Jet Surface Metallurgy," Materials Letters, Vol. 60, No. 11,
2006, pp. 1311-1314. doi:10.1016/j.matlet.2005.10.011

[4] D. E. Wolfe, J. Singh and K. Narasimhan, "Synthesis of Titanium Carbide/Chromium Carbide Multilaryers by the Co-Evaporation of Multiple Ingots by Electron Beam Physical Vapor Deposition," Surface and Coatings Technology, Vol. 160, No. 2-3, 2002, pp. 206. doi:10.1016/S0257-8972(02)00404-8

[5] S. F. Zhou and X. Q. Dai, "Laser Induction Hybrid Rapid Cladding of WC Particles Reinforced NiCrBSi Composite Coatings," Applied Surface Science, Vol. 256, No. 14, 2010, pp. 4708-4714. doi:10.1016/j.apsusc. 2010.02 .078

[6] S. F. Wang, H. Q. Li, X. Chen, et al., "Improving Microstructure and Wear Resistance of Plasma Clad Fe-Based Alloy Coating by a Mechanical Vibration Technique during Cladding," Materials Science and Engineering A, Vol. 528, No. 1, 2010, pp. 397-401. doi:10.1016/j.msea.2010.09.021

[7] S. Buytoz, "Microstructural Properties of $\mathrm{M}_{7} \mathrm{C}_{3}$ Eutectic Carbides in a Fe-Cr-C alloy," Materials Letters, Vol. 60, No. 5, 2006, pp. 605-608. doi:10.1016/j.matlet.2005.09.046

[8] L. Sexton, S. Lavin, G. Byme and A. Kennedy, "Laser Cladding of Aerospace Materials," Journal of Materials Processing Technology, Vol. 122, No. 1, 2002, pp. 63-68. doi:10.1016/S0924-0136(01)01121-9. 